\section{Commentary: Aortic valve intervention in children: The jury is still out}

\author{
Christian Pizarro, MD
}

Management of significant aortic valve disease in children remains a significant challenge, largely due to a number of factors, including concomitant presence of associated lesions requiring intervention, lack of an appropriate-size prosthesis, lack of growth potential, and the desire to avoid anticoagulation. In this scenario, the use of a pulmonary autograft in the aortic position (Ross procedure) has become a common and effective option to relieve significant stenosis and/or regurgitation, particularly in the smallest patients, albeit at the price of reconstruction of the pathway between the right ventricle and the pulmonary artery and the associated need for recurrent reinterventions. Alternatively, complex aortic valve repair with pericardial reconstruction is being increasingly used in some centers as an alternative to avoid the creation of a "double valve" condition.

Acknowledging that the ultimate goal is the preservation of left ventricular function with the least number of reinterventions, neither approach provides a final and reinterventionfree solution; hence the question about the durability of each management strategy.

Despite its inherent technical challenges, it seems obvious that the Ross procedure would be preferred for a number of practical reasons, including applicability to the smallest patients, avoidance of anticoagulation, ability to provide the necessary size matching for a given patient size, and avoidance of growth restriction over time. On the other hand, older children with a larger annulus may be amenable to repair and reconstruction with autologous pericardium, providing a midterm solution and potentially

\footnotetext{
From the Division of Cardiothoracic Surgery, Department of Surgery, Nemours Cardiac Center, Alfred I. duPont Hospital for Children, Wilmington, Del.

Disclosures: The author reported no conflicts of interest.

The Journal policy requires editors and reviewers to disclose conflicts of interest and to decline handling or reviewing manuscripts for which they may have a conflict of interest. The editors and reviewers of this article have no conflicts of interest.

Received for publication March 18, 2021; revisions received March 18, 2021; accepted for publication March 18, 2021; available ahead of print March 24, 2021.

Address for reprints: Christian Pizarro, MD, Cardiothoracic Surgery, Nemours Cardiac Center, Alfred I. duPont Hospital for Children, 1600 Rockland Rd, Wilmington, DE 19803 (E-mail: Christian.Pizarro@nemours.org).

J Thorac Cardiovasc Surg 2022;163:1192-3

$0022-5223 / \$ 36.00$

Copyright $($ c 2021 by The American Association for Thoracic Surgery

https://doi.org/10.1016/j.jtcvs.2021.03.065
}

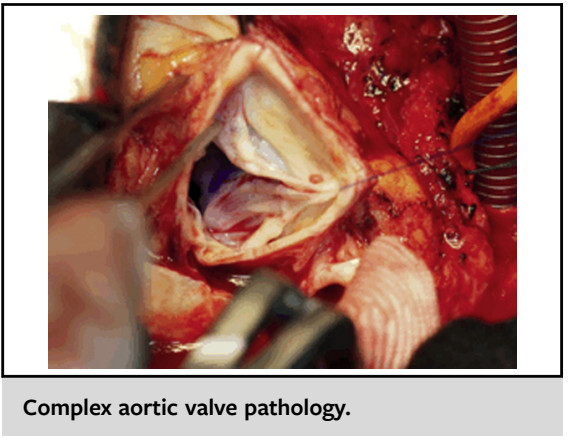

CENTRAL MESSAGE

Aortic valve reconstruction can

be an option as a bridge to

definitive management in

selected children with aortic

valve disease.

a bridge to a conventional aortic valve replacement at a later date, thereby avoiding a more complex procedure, the need for anticoagulation at a younger age, and the creation of a "two-valve condition". Therefore, the real debate centers on the choice between aortic valve repair or replacement with a pulmonary autograft in older children.

In their article in this issue of the Journal, Danial and colleagues ${ }^{1}$ aim to provide some perspective on this controversy by a propensity-matched comparison of 34 patients undergoing either a complex aortic valve repair or a Ross procedure beyond neonatal age. Although there was no difference in operative mortality between the 2 groups, mortality during follow-up was higher in the Ross group. Perhaps not surprising, considering that all these deaths occurred in patients with Shone's anomaly, concomitant interventions at the time of the index procedure and a large proportion of interventions undertaken on an emergency basis. Nevertheless, when it comes to the effectiveness in addressing the primary issue, the freedom from reintervention on the left ventricular outflow tract was substantially lower in the valvuloplasty cohort.

These observations reaffirm the idea that aortic valvuloplasty can provide a suitable interim solution for those patients who in light of their anatomy and size afford the option of avoiding an aortic valve replacement with pulmonary autograft while allowing for growth of the annulus, avoidance of anticoagulation, and an understanding that the systemic valve issue is not resolved and that this is a bridge to a future valve replacement. In the meantime, the 
durability of this approach perhaps could be enhanced by appropriate patient selection and use of more suitable reconstruction materials. The jury is still out.

\section{Reference}

1. Danial O, Naily A, Pontallier M, Gaudin R, Khraiche D, Osborne-Pellegrin M et al. Ross procedure or complex aortic valve repair using pericardium in children: a real dilemma. J Thorac Cardiovasc Surg. 2022;163:1180-91.e6.
See Article page 1180.

\section{Commentary: Aortic valve surgery in children: Repair now, Ross procedure later}

\author{
Edward Buratto, MBBS, PhD, FRACS, ${ }^{\mathrm{a}, \mathrm{b}, \mathrm{c}}$ and \\ Igor E. Konstantinov, MD, PhD, FRACS ${ }^{\mathrm{a}, \mathrm{b}, \mathrm{c}, \mathrm{d}}$
}

Aortic valve surgery in children presents many challenges owing to the need to accommodate ongoing somatic growth. ${ }^{1}$ The 2 widely used surgical techniques, aortic valve repair and the Ross procedure, each carries its own drawbacks. Aortic valve repair has a very low risk of mortality, yet the rate of reoperation is relatively high. ${ }^{2}$ The Ross procedure has excellent freedom from reoperation but an increased risk of mortality in neonates and infants, the need for conduit replacement, and the risk of autograft dilatation and failure, especially in young children in whom the autograft cannot be effectively stabilized. ${ }^{3,4}$ So far, the roles of these 2 techniques have yet to be clearly defined.

In an important article in this issue of the Journal, Danial and colleagues ${ }^{5}$ compare the outcomes of the Ross procedure and complex aortic valve repair (ie, repair necessitating the use of a patch). They report that early mortality was similar in their 2 groups of patients, and that freedom from reoperation for both groups was approximately $50 \%$ at 10 years. They concluded that complex aortic valve repair

\footnotetext{
From the a Department of Cardiac Surgery, Royal Children's Hospital, Melbourne; ${ }^{\mathrm{b}}$ Department of Paediatrics, University of Melbourne, Melbourne; ${ }^{\mathrm{c}}$ Heart Research Group, Murdoch Children's Research Institute, Melbourne; and ${ }^{\mathrm{d}}$ Melbourne Centre for Cardiovascular Genomics and Regenerative Medicine, Melbourne, Australia.

Disclosures: The authors reported no conflicts of interest.

The Journal policy requires editors and reviewers to disclose conflicts of interest and to decline handling or reviewing manuscripts for which they may have a conflict of interest. The editors and reviewers of this article have no conflicts of interest.

Received for publication March 17, 2021; revisions received March 17, 2021; accepted for publication March 18, 2021; available ahead of print March 24, 2021.

Address for reprints: Igor E. Konstantinov, MD, PhD, FRACS, Department of Cardiac Surgery, Royal Children's Hospital, Flemington Rd, Parkville 3052, Australia (E-mail: igor.konstantinov@rch.org.au).

J Thorac Cardiovasc Surg 2022;163:1193-4 $0022-5223 / \$ 36.00$

Crown Copyright $(\subset) 2021$ Published by Elsevier Inc. on behalf of The American Association for Thoracic Surgery

https://doi.org/10.1016/j.jtcvs.2021.03.064
}

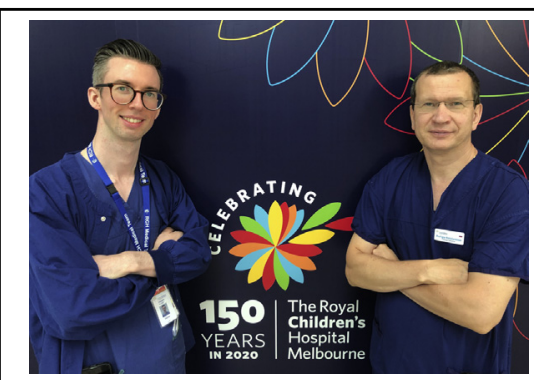

Edward Buratto, MBBS, PhD, FRACS, and Igor E. Konstantinov, MD, PhD, FRACS at the Royal Children's Hospital.

\section{CENTRAL MESSAGE}

Aortic valve repair may postpone

a Ross operation into adoles-

cence or adulthood, when the autograft can be effectively

stabilized.

may be used as a first-line strategy, allowing the Ross to be delayed into later childhood or adulthood.

Over the last few years, it has become increasingly apparent that an initial approach of surgical aortic valve repair in children provides excellent survival and acceptable freedom from reoperation. ${ }^{1-7}$ A strategy of avoiding balloon dilatation with uncontrolled tear of the aortic valve allows for a good quality initial repair and as such results in better freedom from reintervention. ${ }^{6,7}$ Although the Ross procedure is associated with increased mortality in infants and neonates, it has excellent outcomes in older children. ${ }^{4}$ We have recently demonstrated that the autograft has improved durability when the Ross procedure is performed as a reoperation, presumably due to a degree of natural stabilization from postoperative scarring. ${ }^{3}$ Furthermore, excellent results have been demonstrated with the Ross procedure in adolescents and young adults with stabilization of the autograft. ${ }^{8}$ As such, we have increasingly aimed to repair valves, with the hope of delaying the Ross procedure until the child is fully grown and the autograft can be stabilized. 